\title{
Elevated expression of transforming growth factor $\beta 3$ in carbon tetrachloride-treated rat liver and involvement of retinoid signaling
}

\author{
YOSHIHIRO MEZAKI $^{1}$, MAYAKO MORII ${ }^{2}$, KIWAMU YOSHIKAWA $^{1}$, NORIKO YAMAGUCHI $^{1}$, \\ KIYOFUMI SATOYOSHI ${ }^{3}$, MITSUTAKA MIURA ${ }^{1}$, KATSUYUKI IMAI ${ }^{1}$, TATSUZO HEBIGUCHI ${ }^{2}$, \\ TOMONORI HABUCHI ${ }^{3}$ and HARUKI SENOO ${ }^{1}$ \\ Departments of ${ }^{1}$ Cell Biology and Morphology, ${ }^{2}$ Pediatric Surgery and ${ }^{3}$ Urology, Akita University \\ Graduate School of Medicine, Akita 010-8543, Japan
}

Received July 30, 2011; Accepted September 13, 2011

DOI: 10.3892/ijmm.2011.809

\begin{abstract}
Transforming growth factor (TGF) $\beta$ is a pro-fibrotic cytokine. While three isoforms (TGF- $\beta 1,2$ and 3 ) are known, the functional differences between them are obscure. To investigate the roles of TGF- $\beta$ isoforms during liver fibrogenesis, male Wistar rats were administrated carbon tetrachloride $\left(\mathrm{CCl}_{4}\right)$ subcutaneously twice a week for two months. Livers were excised and sectioned for histochemical examinations. These livers were also used to quantitate the expression of genes associated with fibrogenesis, including TGF- $\beta$ isoforms, as well as those associated with retinoid metabolism. Expression levels of $T g f b 1$ and $T g f b 3$ were up-regulated in $\mathrm{CCl}_{4}$-treated rat livers while that of $T g f b 2$ was not changed. The mRNAs for lecithin-retinol acyltransferase (Lrat) and retinoic acid hydroxylase, Cyp26al, were also elevated. By immunohistochemical staining, TGF- $\beta 3$ protein was found to be localized mainly in liver parenchymal cells (hepatocytes). These results indicate that retinoid mobilization likely takes place within the rat's liver following $\mathrm{CCl}_{4}$ treatment, and suggest the possibility that the expression of $T g f b$ mRNA is regulated by retinoic acid receptors. Reporter analyses of a region of the $T g f b 3$ gene were performed using the rat liver parenchymal cell line, RLC-16, and a positively responsive region was identified within its intron.
\end{abstract}

\section{Introduction}

Exposure to carbon tetrachloride $\left(\mathrm{CCl}_{4}\right)$ has hepatotoxic effects, including fatty degeneration and fibrosis. These

Correspondence to: Dr Yoshihiro Mezaki, Department of Cell Biology and Morphology, Akita University Graduate School of Medicine, 1-1-1 Hondo, Akita 010-8543, Japan

E-mail: mezaki@gipc.akita-u.ac.jp

Key words: liver, carbon tetrachloride, transforming growth factor $\beta$, vitamin A, retinoic acid receptor effects are initiated by highly reactive radicals such as $\mathrm{CCl}_{3}$. and $\mathrm{CCl}_{3} \mathrm{OO} \cdot$, which can modify DNA, lipids, protein and carbohydrates (1). These radicals also damage membranous structures, such as the plasma membrane, endoplasmic reticulum, mitochondria, and the Golgi apparatus through lipid peroxidation. These modifications of cellular components and organelles lead to a loss of $\mathrm{Ca}^{2+}$ homeostasis, reduced protein synthesis, apoptosis, and DNA mutation (1). Many factors, including cytokines, chemokines, $\mathrm{NO}$, and bile acids are proposed to mediate the hepatotoxic effects of $\mathrm{CCl}_{4}(2)$. Among those factors mediating $\mathrm{CCl}_{4}$-induced fibrogenesis, TGF- $\beta$ is the most important and well-studied cytokine (3-5). TGF- $\beta$ was originally identified as a protein inducing anchorage-independent growth of non-neoplastic cells $(6,7)$. It was later revealed to be involved in many cellular processes including cell proliferation, differentiation, motility, adhesion, and death. Mammalian TGF- $\beta$ has three isoforms which are encoded by different genes and these three isoforms show similarities both structurally and functionally. TGF- $\beta$ binds to specific receptors on the cell surface, and binding signals are transduced into the nucleus by Smad proteins. There, collagen gene expression is up-regulated, leading to the production and deposition of collagen proteins within the liver (5).

It is known that hepatic stellate cells, which reside within the perisinusoidal space between hepatic cords and liver sinusoidal endothelial cells, are involved in the fibrotic process $(8,9)$. Another remarkable feature of hepatic stellate cells upon cirrhosis is the loss of vitamin A. However, the implication of this decrease in vitamin A within the liver is totally unknown. Vitamin A is obtained from foods in the form of the retinyl ester or $\beta$-carotene, and once converted to retinol in the intestine, it is carried in the bloodstream as retinyl ester to the liver, where it is stored for future usage $(10,11)$. In target cells, vitamin A is converted to active metabolites (retinoids) which bind to nuclear transcription factors, retinoic acid receptors (RARs) and retinoid X receptors (RXRs), to activate transcription of their target genes $(12,13)$ through retinoic acid response elements (RAREs) within gene promoters.

In this study of $\mathrm{CCl}_{4}$-induced fibrosis of rat livers, we analyzed changes in mRNAs related not only to fibrogenesis, 
but also to retinoid metabolism. A possible link between TGF- $\beta$ signaling and retinoic acid signaling was also analyzed in this study.

\section{Materials and methods}

Materials. $\mathrm{CCl}_{4}$, liquid paraffin, and all-trans retinoic acid (RA) were from Wako Pure Chemical (Osaka, Japan). Retinol (ROL) was purchased from Sigma-Aldrich (St. Louis, MO, USA). Dulbecco's modified Eagle's medium (DMEM) and fetal bovine serum (FBS) were from Invitrogen (Carlsbad, CA, USA) and Vitromex (Vilshofen, Germany), respectively. Oligonucleotides were synthesized by Invitrogen. The mouse embryonal teratocarcinoma cell line, F9 (RCB1555), and the rat liver parenchymal cell line, RLC-16 (RCB1474) were provided by the RIKEN Cell Bank (Tsukuba, Japan).

Animals. Protocols for animal experimentation were approved by the Animal Research Committee, Akita University Graduate School of Medicine. All animal experiments adhered to the 'Guidelines for Animal Experimentation' of the University. Male Wistar rats, 6 weeks of age, and weighing between 165-175 g, were injected subcutaneously with $0.3 \mathrm{ml}$ of $\mathrm{CCl}_{4}$ per $\mathrm{kg}$ of body weight, in liquid paraffin (1:9 mixture), twice a week for two months (a total of 17 times). Rats were then anaesthetized, and livers were excised and immersed in $10 \%$ formalin for fixation and then embedded in paraffin for sectioning. For RNA preparation, small pieces of livers were quick-frozen in liquid nitrogen and kept frozen at $-85^{\circ} \mathrm{C}$. At the time of sacrifice, rats weighed 360-430 g.

RNA extraction and quantitative RT-PCR. Frozen rat livers were lysed in TRIzol reagent (Invitrogen), and total-RNA was isolated according to the manufacturer's protocols. Then, cDNAs were synthesized from $5 \mu \mathrm{g}$ of total-RNA using SuperScript III Reverse Transcriptase (Invitrogen) with an oligo(dT)18 primer. Quantification of cDNA was conducted with the LightCycler 480 SYBR-Green I Master (Roche Diagnostics, Meylan, France) according to the manufacturer's instructions. The primer sequences used are listed in Table I. PCR reactions were performed in triplicate, and standard deviations were calculated. Transcript amounts were normalized against the Gapdh transcript, and transcription levels in the normal liver were set to 1.0 for each gene.

The mouse embryonal teratocarcinoma cell line, F9, was cultured in RPMI-1640 medium supplemented with 10\% FBS. $\mathrm{RA}$ in ethanol or ethanol alone was added to $10 \mathrm{~cm}$ culture dishes to a final concentration of $0.1 \mu \mathrm{M}$. After $24 \mathrm{~h}$ cultivation, cells were treated as above with $2 \mathrm{ml}$ of TRIzol reagent for quantification of mRNAs for $T g f b 1, T g f b 2, T g f b 3$ and $R a r b$.

Immunohistochemistry. Paraffin-embedded livers were sectioned at $3 \mu \mathrm{m}$ intervals and de-paraffinized by immersion in xylene. Buffers were substituted sequentially with 100, 90, 80, 70 and $50 \%$ ethanol. Specimens were treated in boiled citrate buffer $(0.01 \mathrm{M})$ in order to unmask the antigens and then cooled to room temperature. For inactivation of endogenous peroxidase activity, slides were immersed in $1 \% \mathrm{H}_{2} \mathrm{O}_{2}$ for $20 \mathrm{~min}$. Slides were treated with $2 \%$ bovine serum albumin (BSA) in phosphate-buffered saline containing $0.1 \%$ Tween-20 (PBST) to block non-specific binding of antibodies. Slides were then incubated with rabbit polyclonal anti-TGF- $\beta 1$ antibody (1:50 dilution, sc-146, Santa Cruz Biotechnology, Santa Cruz, CA, USA) or rabbit polyclonal anti-TGF- $\beta 3$ antibody (1:50 dilution, sc-82, Santa Cruz Biotechnology) in PBST plus 2\% BSA for $2 \mathrm{~h}$ at room temperature. After washing, slides were treated with a 1:500 dilution of peroxidase-conjugated AffiniPure goat anti-rabbit IgG. After washing, slides were incubated with DAB substrate (Roche Diagnostics) for $30 \mathrm{~min}$. Nuclei were counterstained with Mayer's hematoxylin solution (Wako Pure Chemical). Slides were washed with water and then immersed with 20, 40, 80 and $100 \%$ ethanol and finally, 100\% xylene. Dried slides were sealed with Entellan new (Merck, Darmstadt, Germany) and recorded digitally using NanoZoomer Digital Pathology (Hamamatsu Photonics, Hamamatsu, Japan).

Plasmids. The genomic sequence of rat $T g f b 3$ was obtained from the Ensembl database (ENSRNOT00000013516). The intronic sequence connecting exons 3 and 4 (4001-5390, numbers designate nucleotide positions within the intron) was amplified by PCR using a RoboCycler (Stratagene, La Jolla, CA, USA) with primers containing KpnI and XhoI overhangs and inserted in the pGL4.26 vector (Promega, Madison, WI, USA). The cloned fragment was verified by sequencing. There was an insertion of TGTGTG after 4087 and substitutions from $A \rightarrow G$ at 4156 and $A \rightarrow C$ at 5078. Though there is an insertion within the cloned fragments, we employed nucleotide numbering based on the database sequence. The reporter plasmid containing retinoic acid responsive element was used as a positive control as described elsewhere (14).

Mutagenesis of the cloned intronic sequence (putativeRARE) was performed as described (15) using the primer pairs CACTCCTGTAAAGACGCCACTATTGACCCAACC/ GGTTGGGTCAATAGTGGCGTCTTTACAGGAGTG for putativeRAREm1, TAAAGACTGAACTATGCTCCCAACC TTCACTTC/GAAGTGAAGGTTGGGAGCATAGTTCAGT CTTTA for putativeRAREm2, and TAAAGACGCCACTAT GCTCCCAACCTTCACTTC/GAAGTGAAGGTTGGGAGC ATAGTGGCGTCTTTA for putativeRAREm12, respectively. Underlines indicate the mutated residues.

Transfection and luciferase assay. Transfection of plasmids into the rat liver parenchymal cell line RLC-16 was conducted with Lipofectamine 2000 reagent (Invitrogen). Two hundred and $50 \mathrm{ng}$ of each reporter plasmid, pcDNA3.1-rRAR $\alpha$ and pcDNA3.1-rRXR $\alpha$, along with $12.5 \mathrm{ng}$ of pRL-CMV (Promega) as an internal control, were transfected in 12-well formats. Three hours after transfection, the medium was changed and ligands were added. Twenty-four hours after ligand addition, cells were lysed and luciferase activities were measured using the Dual Luciferase Reporter Assay System (Promega) with a luminescence reader (BLR-201, Aloka, Tokyo, Japan). Luciferase activity from the experimental reporter plasmid was normalized against luciferase activity from the control pRL-CMV plasmid in the same well. Three independent cultures were used for each luciferase assay, and the calculated standard deviations are indicated in the figures.

Statistical analysis. Statistical analyses were performed using the Hulinks KaleidaGraph software. Data are expressed as 
Table I. Primers for RT-PCR.

\begin{tabular}{|c|c|c|c|c|}
\hline Species & Gene & Forward & Reverse & Length (bp) \\
\hline Rat & Gapdh & acagcaactcccattcttcc & tccaccaccetgttgetgta & 118 \\
\hline Rat & Collal & acagtcgattcacctacagc & tgtccaagggagccacatcg & 132 \\
\hline Rat & Colla2 & attcacctacactgtccttg & atgtccagaggtgcaatgtc & 123 \\
\hline Rat & Col3a1 & cacttacacagttctagagg & atgtcatagggtgcgatatc & 123 \\
\hline Rat & Col4al & actacgcgaatgcttacagc & ctcatgcacacttggcagcg & 130 \\
\hline Rat & $T g f b 1$ & ccatgccaacttctgtctggg & ggcacgcagcacggtgatg & 123 \\
\hline Rat & $T g f b 2$ & cttatctgtggagttcagac & gccaatgtagtagaggatgg & 134 \\
\hline Rat & $T g f b 3$ & tacctccgcagctcagacac & ttctgccaacatagtacaag & 136 \\
\hline Rat & Rxra & cggtgtcagtactgccgata & ctccacctcattctcgttcc & 108 \\
\hline Rat & Rara & ctgtttgetccaggagaagg & gaactgctgctctgggtctc & 111 \\
\hline Rat & Rarb & ctctcaaagcctgcctcagt & cgagctcctcagagctggta & 99 \\
\hline Rat & Rarg & cagccaaccctacatgttcc & tcgaggagtcgtcctcaaac & 173 \\
\hline Rat & Ppara & atttccctttttgtggctgc & tggttgctctgcaggtggag & 125 \\
\hline Rat & Pparb/d & tcattgccgecatcattctg & ctgtcggggtggttgacctg & 124 \\
\hline Rat & Pparg & ggaattagatgacagtgact & gcctgcagcaggttgtcttg & 117 \\
\hline Rat & Cyp26al & aggctggatatgcaggcact & tggctcttgcaaagtaagcc & 170 \\
\hline Rat & Lrat & gcgaacactttgtgacctac & gacagctgaagcaagacaac & 119 \\
\hline Rat & Rbp4 & gttttctcgtgaccccaatg & actgtttcttgagggtctgc & 139 \\
\hline Rat & $R b p 1$ & aggcatagatgaccgcaagt & tcatcaccctcaatccactg & 117 \\
\hline Rat & Crabp2 & tgtgcgaacagaggcttctg & ctcggacgtagaccctggtg & 129 \\
\hline Mouse & Gapdh & accacagtccatgccatcac & cttggcagcaccagtggatg & 120 \\
\hline Mouse & $T g f b 1$ & cctcatggecaccecctg & tcaatgtacagctgccgcacac & 126 \\
\hline Mouse & $T g f b 2$ & catatctatggagttcagac & tccaatgtaatagagaatgg & 134 \\
\hline Mouse & $T g f b 3$ & tacctccgcagcgcagacac & ttctgcccacatagtacaag & 136 \\
\hline Mouse & Rarb & same as the sequences for rat & & \\
\hline
\end{tabular}

means \pm standard deviation (SD). The statistical significance of the differences was evaluated by the unpaired Student's t-test for data in Figs. 2 and 5 and by one-way analysis of variance (ANOVA) combined with the Tukey test for data in Fig. 4. $\mathrm{P}$-values $<0.05$ were considered to be statistically significant.

\section{Results}

$\mathrm{CCl}_{4}$-induced liver fibrosis. Liver fibrogenesis induced by chronic administration of $\mathrm{CCl}_{4}$ was confirmed by Azan staining (Fig. 1). As was previously demonstrated, fibrotic areas were mainly distributed around central veins (Fig. 1C and D) and steatosis of parenchymal cells was also observed.

Expression of various genes involved in fibrogenesis as well as retinoid metabolism in $\mathrm{CCl}_{4}$-treated rat liver. We quantified mRNA levels in the livers of normal and $\mathrm{CCl}_{4}$-injected rats. We focused on genes associated with fibrogenesis, as well as those associated with retinoid metabolism, because it is known that retinoid loss is a frequently observed symptom in liver cirrhosis $(8,9)$. As shown in Fig. 2, types I (Collal and Colla2) and type III (Col3al) collagen, which constitute a major portion of liver fibrosis, were up-regulated in $\mathrm{CCl}_{4}$-treated rat livers. Type IV collagen (Col4al), which is a main component of basal lamina, was also up-regulated. Among the TGF- $\beta$ s, the most important cytokines for hepatic fibrogenesis, $T g f b 1$ and $T g f b 3$ were up-regulated 2.4- and 7.1-fold, respectively, while $T g f b 2$ was not significantly altered. Rxra, whose ligand is 9-cis retinoic acid, and Rara, Rarb and Rarg, whose ligand is all-trans retinoic acid, were all up-regulated in $\mathrm{CCl}_{4}$-treated rat livers, though the increase in Rara was not significant. Peroxisome proliferator-activated receptors (Ppara, Pparb/d, Pparg), which are transcription factors responsible for lipid metabolism and energy consumption, were also up-regulated. Cyp26al, the gene for a P450 enzyme, CYP26A1, which catalyzes hydroxylation of retinoic acid for its elimination, was greatly up-regulated. The gene for lecithin-retinol acyltransferase (Lrat), which esterifies retinol to make retinylesters, was also up-regulated. The genes encoding RBP (Rbp4), CRBP-I $(R b p 1)$, and CRABP-II (Crabp2), which are serum retinol, cellular retinol, and cellular retinoic acid binding proteins, respectively, were slightly up-regulated in $\mathrm{CCl}_{4}$-treated rat livers.

Immunohistochemical localization of TGF- $\beta$ s in $\mathrm{CCl}_{4}$-treated rat liver. Quantitative RT-PCR analyses revealed that TGF- $\beta$ isoforms were differentially regulated in $\mathrm{CCl}_{4}$-treated rat livers (Fig. 2). We thus used immunohistochemical methods to assess the localization of the TGF- $\beta$ isoforms. Mature TGF- $\beta$ isoforms are very similar to one another; TGF- $\beta 3$ is $\sim 80 \%$ similar to TGF- $\beta 1$ and TGF- $\beta 2$, while TGF- $\beta 2$ is $72 \%$ similar to TGF- $\beta 1$ (16). Therefore, cross-reactivity of antibodies against TGF- $\beta$ 

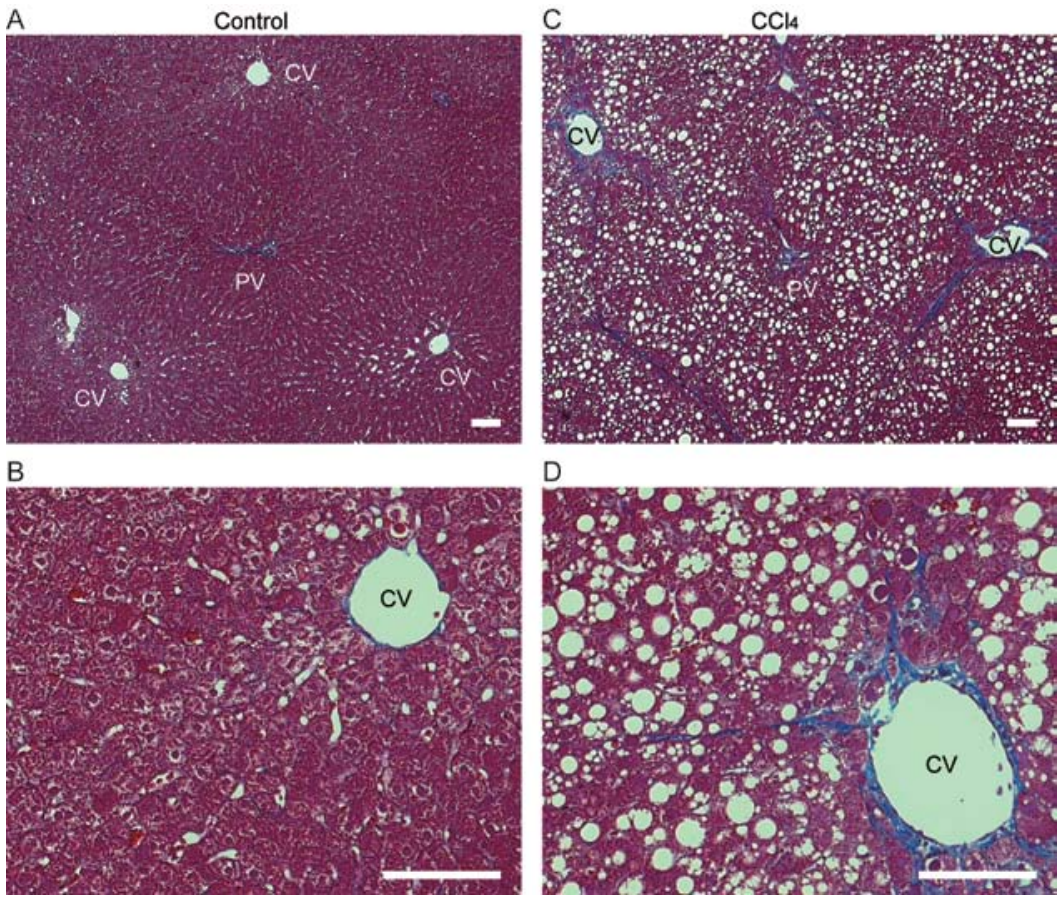

Figure 1. Carbon tetrachloride $\left(\mathrm{CCl}_{4}\right)$-induced liver fibrosis. Male Wistar rats were administered $\mathrm{CCl}_{4}$ in liquid paraffin $(\mathrm{C}$ and $\mathrm{D})$ or liquid paraffin alone (A and B) subcutaneously twice a week for two months. Livers were excised and sectioned for Azan staining. (B and D) Magnifications of central vein regions of panels (A) and (C), respectively. PV, portal vein; CV, central vein. Scale bars, $100 \mu \mathrm{m}$.

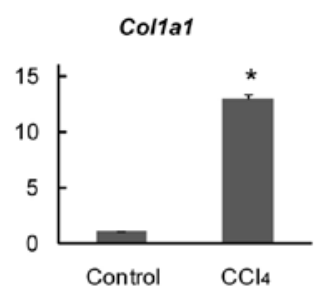

Tgfb2

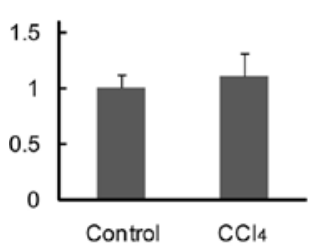

Rarg

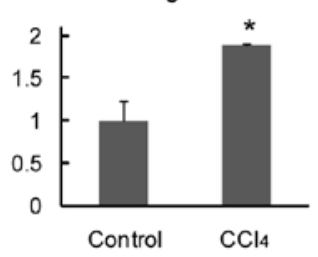

Lrat

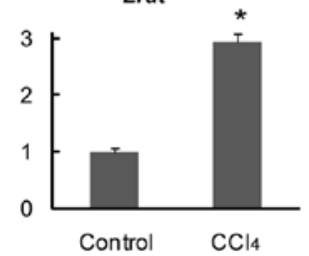

Col1a2

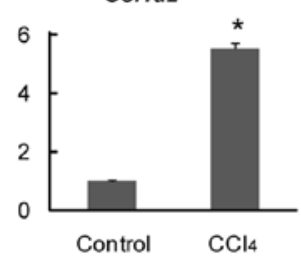

$\operatorname{Tgfb3}$

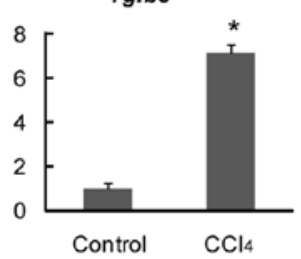

Ppara

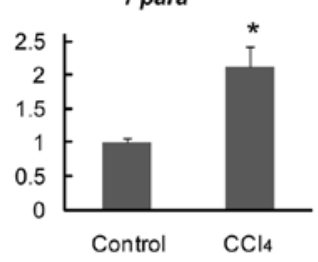

Rbp4

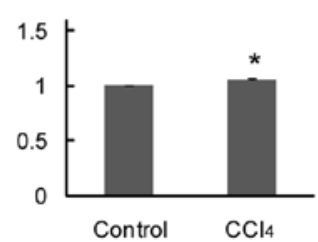

Col3a1

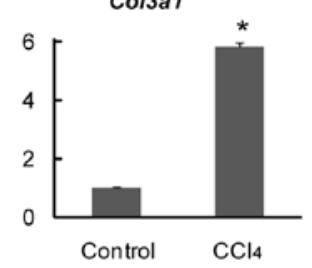

Rxra

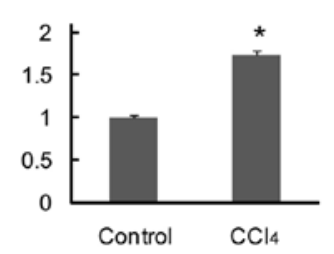

Pparb/d

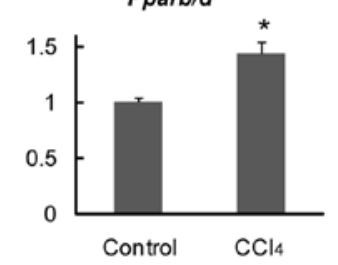

Rbp1

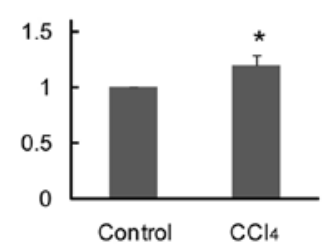

Col4a1

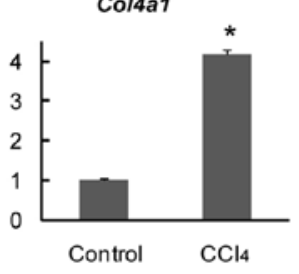

Rara

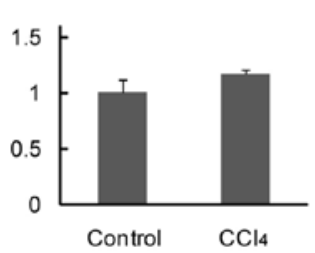

Pparg

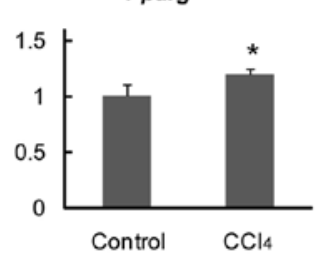

Crabp2

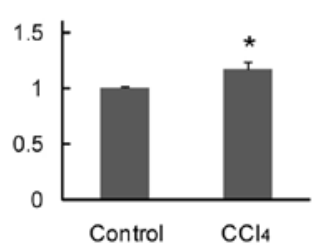

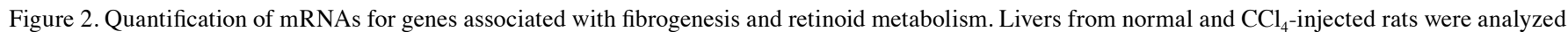
for mRNA expression by quantitative RT-PCR using the primer sequences listed in Table I. Transcript levels were normalized against the Gapdh transcript, and the transcript levels of normal liver were set to 1.0 for each gene. ${ }^{*} \mathrm{p}<0.05$ vs. control. 

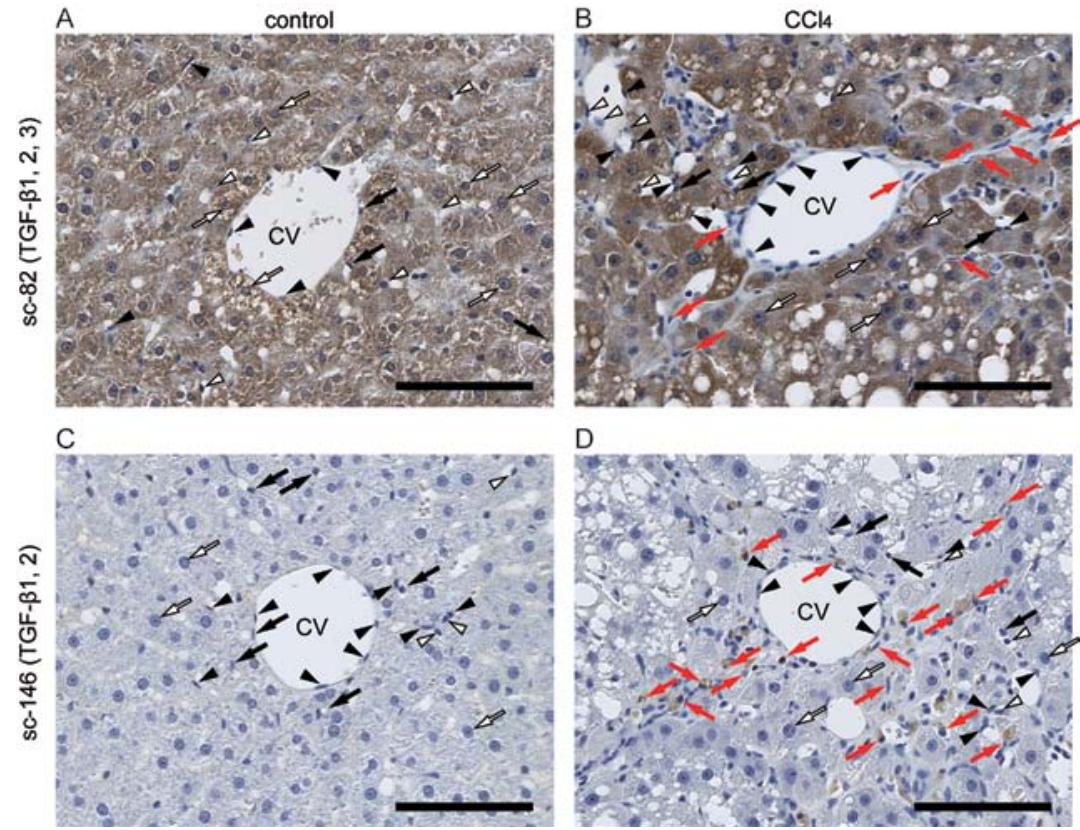

Figure 3. Immunohistochemical staining of control (A and C) and $\mathrm{CCl}_{4}$-injected (B and D) rat livers by sc-82 (A and B) or sc-146 (C and D) antibodies. The sc-82 antibody detects TGF- $\beta 1,-\beta 2$, and $-\beta 3$ and the sc-146 antibody detects TGF- $\beta 1$ and $-\beta 2$. Nuclei were counterstained with hematoxylin. CV, central vein. Open arrows, parenchymal cells. Solid arrows, hepatic stellate cells. Open arrowheads, Kupffer cells. Solid arrowheads, endothelial cells. Red arrows, mesenchymal cells. Scale bars, $100 \mu \mathrm{m}$.

isoforms is very common. The commercially available antiTGF- $\beta 1$ antibody sc-146 (Fig. 3C and D) actually cross-reacts with TGF- $\beta 2$, and antibody sc-82 (Fig. 3A and B), nominally an anti-TGF- $\beta 3$ antibody, cross-reacts with both TGF- $\beta 1$ and $-\beta 2$, per the manufacturer. In spite of the cross-reactivity of the sc-146 antibody (which detects TGF- $\beta 1$ and $-\beta 2$ ), it stained very few cell types in $\mathrm{CCl}_{4}$-treated rat liver sections (Fig. 3D) and almost none in normal rat liver sections (Fig. $3 \mathrm{C}$ ). $\mathrm{In} \mathrm{CCl}_{4^{-}}$ treated rat livers, some non-parenchymal mesenchymal cells within pseudolobes or septa were positive for sc-146 staining (red arrows in Fig. 3D). Positive cells were more abundant in the central region than in the portal region, which is consistent with the fibrogenic tendency induced by $\mathrm{CCl}_{4}$ (Fig. 1). Parenchymal cells (Fig. 3, open arrows), hepatic stellate cells (Fig. 3, solid arrows), Kupffer cells (Fig. 3, open arrowheads) and endothelial cells (Fig. 3, solid arrowheads) were generally negative for sc-146 staining both in normal and degenerated rat livers.

On the other hand, immunohistochemical staining by sc- 82 antibody (which detects all three isoforms of TGF- $\beta$ ) showed strong staining of hepatocytes both in normal (Fig. 3A) and degenerated livers (Fig. 3B). Staining of non-parenchymal mesenchymal cells within the septa (Fig. 3B) was generally weak compared to that of hepatocytes. Taking into account the antibody specificity described above, strong staining of parenchymal cells in normal and $\mathrm{CCl}_{4}$-treated rat livers is due to the presence of TGF- $\beta 3$ in these cells. Parenchymal staining in $\mathrm{CCl}_{4}$-injected livers was more intense than that in normal livers, which may reflect the induction of $T g f b 3 \mathrm{mRNA}$ in $\mathrm{CCl}_{4}$-treated rat livers (Fig. 2). Hepatic stellate cells (Fig. 3, solid arrows), Kupffer cells (Fig. 3, open arrowheads), endothelial cells (Fig. 3, solid arrowheads) seemed to be negative for sc-82 staining, though it was difficult to discriminate the cytoplasm of these cells from that of the parenchymal cells adjacent to these cells.
Retinoic acid-responsiveness of an intronic region of the $T g f b 3$ gene. TGF- $\beta$ up-regulation in $\mathrm{CCl}_{4}$-treated rat livers, especially the TGF- $\beta 3$ isoform, as well as the up-regulation of genes associated with retinoid metabolism such as Cyp26al and Lrat, led us to the idea that TGF- $\beta$ expression may be regulated by retinoid signaling. Retinoic acid responsive elements were defined by either DR5 (direct repeat of $(\mathrm{A} / \mathrm{G}) \mathrm{G}(\mathrm{G} / \mathrm{T}) \mathrm{TCA}$ intervened by any five nucleotides) or DR2 (direct repeat of (A/G)G(G/T)TCA with any two intervening nucleotides) elements. Therefore, we searched for such elements in the $T g f b l$ and $T g f b 3$ genes. Within an intron, which intercalates between exons 3 and 4 of $T g f b 3$, a DR2 type of RARE 4322-GGGTCAatAGTTCA-4309 (numbers represent nucleotide positions within the intron and lower case letters indicate intervening nucleotides between two direct repeat sequences) was discovered (Fig. 4). A fragment containing this putative RARE was cloned and incorporated in a pGL4.26 vector (Fig. 4), which contained a minimal promoter between multiple cloning site and the luciferase gene. A defined sequence of the DR5 type of RARE was used as a positive control. As shown in Fig. 4, the region within intron 3-4 of the Tgfb3 gene, which contains a putative DR2 type of RARE, was positively regulated by RA. This sequence was then mutated to GGGTCAatAGTGGC (putativeRAREm1), or GGGAGCatAGTTCA (putativeRAREm2), or GGGAGCatAGTGGC (putativeRAREm12), and these constructs were analyzed by the luciferase assay (Fig. 4). None of these mutants responded to RA, confirming that this specific element is responsible for the retinoid responsiveness within this DNA fragment.

Retinoic acid-mediated up-regulation of mRNAs for TGF- $\beta$ isoforms in cultured cells. We also asked whether the DR2 element in the intronic region was present in the mouse $T g f b 3$ gene and found that this element was conserved in rat and mouse (4392-GGGTCAggAGTTCA-4379), though this element was 

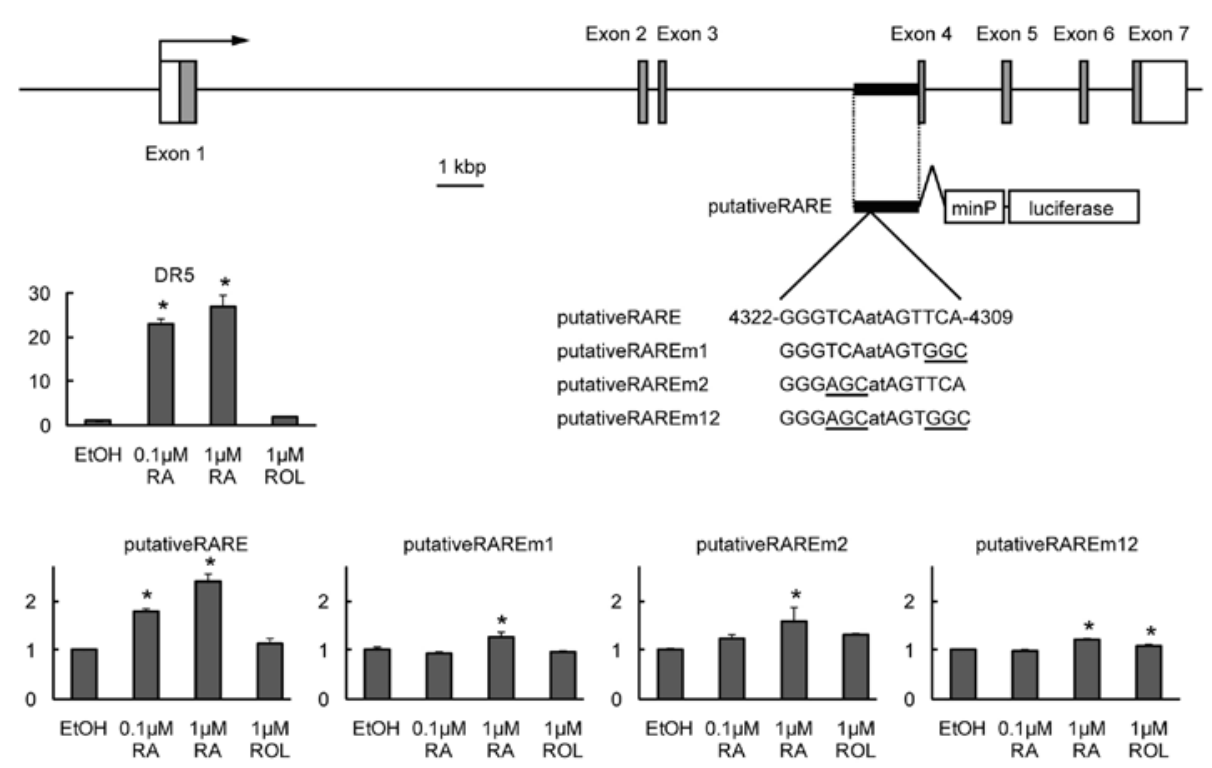

Figure 4. Exon-intron structure and retinoic acid-responsiveness of the rat $T g f b 3$ gene. Upstream and downstream open boxes represent the 5'-untranslated region (UTR) and 3'-UTR, respectively. Seven closed boxes between two UTRs represent amino acid coding regions. A bold bar between exon 3 and 4 represents an intronic sequence used in the reporter assay. The intronic sequence was incorporated in pGL4.26 vector and transfected into a rat liver parenchymal cell line, RLC-16. Twenty-four hours after retinoid addition, cells were collected and luciferase activities were measured. The underlined sequence segments indicate the mutated residues. " $\mathrm{p}<0.05$ vs. control.
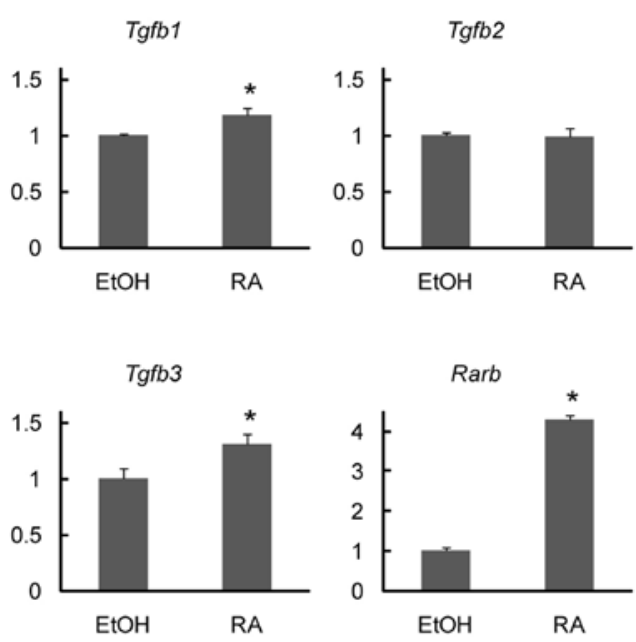

Figure 5. The effects of retinoid on gene expression of TGF- $\beta$ isoforms in cultured cells. A mouse embryonal teratocarcinoma cell line, F9, was treated with $0.1 \mu \mathrm{M}$ all-trans retinoic acid (RA). After $24 \mathrm{~h}$ cultivation, cells were collected and assessed for mRNA expression by quantitative RT-PCR. Transcript levels were normalized against Gapdh transcript, and the transcript levels of control cells were set to 1.0 for each gene. As a representative RA-responsive gene, Rarb mRNA was quantified. " p $<0.05$ vs. control.

not conserved in the human $T g f b 3$ gene (data not shown). We then examined a mouse teratocarcinoma cell line F9 (positive for RAR $\alpha, \beta$ and $\gamma$ ), to determine whether the expression of TGF- $\beta$ isoforms was altered in response to RA (Fig. 5). The mRNA levels for the Rarb gene, which has a definitive RARE in its promoter region, increased in RA-treated F9 cells, confirming the presence of retinoid-responsiveness in F9 cells used in this experiment. As shown in Fig. 5, minor increases in $T g f b 1$ (1.2-fold) and $T g f b 3$ isoforms (1.3-fold) were observed in RA-treated F9 cells, indicating that the expression of TGF- $\beta$ isoforms was up-regulated to some extent in response to RA.

\section{Discussion}

Among TGF- $\beta$ isoforms, TGF- $\beta 1$ protein was the first to be purified from human platelets (7), and the first to be cloned from human placenta (17). In the initial report describing $T g f b l$ cDNA cloning, several tissues and cell lines were assessed by Northern blotting. The liver was reported to be negative for $T g f b l$ mRNA (17). However, the same group later reported moderate expression of $T g f b l$ in rat liver (16). Another report using Northern blotting techniques stated that TGF- $\beta 1$ was the most abundant isoform in both normal and $\mathrm{CCl}_{4}$-treated rat livers (18). The lowest level of $T g f b l$ mRNA was found in normal adult mouse liver, while neonatal mouse liver $T g f b l$ mRNA expression was 2-fold higher than in adult liver (19). By protein detection techniques such as immunohistochemistry, normal human livers were reported to be negative for TGF- $\beta 1$ staining, though fibrotic areas with chronic active hepatitis were positive for TGF- $\beta 1$ (20). Biliary ductular cells and hepatocytes of mouse liver were reported to be weakly positive for TGF- $\beta 1$ staining (19). From these earlier reports and our present data (Figs. 2 and 3), we speculate that in normal liver, very limited numbers of cells are positive for TGF- $\beta 1$, and in cirrhotic conditions, more cells become TGF- $\beta 1$-positive, though it is not certain if these TGF- $\beta 1$-positive cells develop within the liver or are derived from the circulation.

Using immunohistochemistry in this report, we showed that TGF- $\beta 3$ protein is widely distributed in hepatocytes (Fig. 3). We also showed increases in Tgfb3 mRNA upon $\mathrm{CCl}_{4}$ treatment, which was more prominent than the increase in $T g f b 1$ mRNA (Fig. 2). The up-regulation of $T g f b l$ and $T g f b 3$ mRNAs was also observed (though less prominently) following administration of RA in cultured cells (Fig. 5). By reporter analyses of an intronic region of $T g f b 3$ gene, we found that the DNA fragment containing RARE responded positively to RA, suggesting that the up-regulation of $T g f b 3$ mRNA was 
partly mediated by retinoid signaling. The mechanism of up-regulation of $T g f b l$ mRNA upon $\mathrm{CCl}_{4}$ treatment was not revealed in this report. It was reported that $\operatorname{RAR} \alpha, \operatorname{RAR} \beta$, and RXR $\alpha$ down-regulate the $T g f b l$ promoter by binding to AP-1 transcription factors, thus inhibiting their activities (21). It should also be noted that retinoid signaling can modify TGF- $\beta$ activity indirectly. For example, retinoid signaling up-regulates TGF- $\beta$ signaling by inducing the plasminogen activator, which proteolytically converts the latent form of TGF- $\beta$ to an active form (22).

Several former reports stated the importance of TGF- $\beta 3$ in the pathogenesis of liver cirrhosis $(23,24)$. Cirrhotic liver tissue samples from human patients showed increased expressions of $T g f b 1, T g f b 2$ and $T g f b 3$ mRNAs, of which $T g f b 3$ showed the highest level of expression in human liver cirrhosis (23). The up-regulation of $T g f b 3 \mathrm{mRNA}$ was also observed in livers of patients with primary biliary cirrhosis but not in livers of patients with viral cirrhosis (24). These earlier reports as well as our recent report (25) pointed out the possibility of the involvement of biliary epithelial cells in liver cirrhosis. Our present study showed the possibility that the hepatocytes are also involved in the pathogenesis of liver cirrhosis.

In summary, we show that TGF- $\beta 3$ is distributed in parenchymal cells in the liver and up-regulated in $\mathrm{CCl}_{4}$-treated rat livers. We propose that the increase of $T g f b 3 \mathrm{mRNA}$ is partly mediated by retinoid signaling.

\section{Acknowledgements}

This study was supported by KAKENHI (23790269, 23792026 and 23590228).

\section{References}

1. Weber LW, Boll M and Stampfl A: Hepatotoxicity and mechanism of action of haloalkanes: carbon tetrachloride as a toxicological model. Crit Rev Toxicol 33: 105-136, 2003.

2. Jaeschke H, Gores GJ, Cederbaum AI, Hinson JA, Pessayre D and Lemasters JJ: Mechanisms of hepatotoxicity. Toxicol Sci 65: 166-176, 2002.

3. Massague J: The transforming growth factor-beta family. Annu Rev Cell Biol 6: 597-641, 1990.

4. Massague J: TGF-beta signal transduction. Annu Rev Biochem 67: 753-791, 1998.

5. Inagaki $\mathrm{Y}$ and Okazaki I: Emerging insights into transforming growth factor beta Smad signal in hepatic fibrogenesis. Gut 56: 284-292, 2007.

6. Roberts AB, Anzano MA, Lamb LC, Smith JM and Sporn MB: New class of transforming growth factors potentiated by epidermal growth factor: isolation from non-neoplastic tissues. Proc Natl Acad Sci USA 78: 5339-5343, 1981.

7. Assoian RK, Komoriya A, Meyers CA, Miller DM and Sporn MB: Transforming growth factor-beta in human platelets. Identification of a major storage site, purification, and characterization. J Biol Chem 258: 7155-7160, 1983.
8. Friedman SL: Molecular regulation of hepatic fibrosis, an integrated cellular response to tissue injury. J Biol Chem 275: 2247-2250, 2000.

9. Senoo H and Wake K: Suppression of experimental hepatic fibrosis by administration of vitamin A. Lab Invest 52: 182-194, 1985.

10. Napoli JL: Interactions of retinoid binding proteins and enzymes in retinoid metabolism. Biochim Biophys Acta 1440: 139-162, 1999.

11. Blomhoff $\mathrm{R}$ and Blomhoff HK: Overview of retinoid metabolism and function. J Neurobiol 66: 606-630, 2006.

12. Chambon P: A decade of molecular biology of retinoic acid receptors. FASEB J 10: 940-954, 1996.

13. Kishimoto M, Fujiki R, Takezawa S, Sasaki Y, Nakamura T, Yamaoka K, Kitagawa $\mathrm{H}$ and Kato $\mathrm{S}$ : Nuclear receptor mediated gene regulation through chromatin remodeling and histone modifications. Endocr J 53: 157-172, 2006.

14. Mezaki Y, Yoshikawa K, Yamaguchi N, Miura M, Imai K, Kato S and Senoo H: Rat hepatic stellate cells acquire retinoid responsiveness after activation in vitro by post-transcriptional regulation of retinoic acid receptor alpha gene expression. Arch Biochem Biophys 465: 370-379, 2007.

15. Mezaki Y, Yamaguchi N, Yoshikawa K, Miura M, Imai K, Itoh H and Senoo H: Insoluble speckled cytosolic distribution of retinoic acid receptor alpha protein as a marker of hepatic stellate cell activation in vitro. J Histochem Cytochem 57: 687-699, 2009.

16. Derynck R, Lindquist PB, Lee A, Wen D, Tamm J, Graycar JL, Rhee L, Mason AJ, Miller DA, Coffey RJ, Moses HL and Chen EY: A new type of transforming growth factor-beta, TGF-beta 3. EMBO J 7: 3737-3743, 1988.

17. Derynck R, Jarrett JA, Chen EY, Eaton DH, Bell JR, Assoian RK, Roberts AB, Sporn MB and Goeddel DV: Human transforming growth factor-beta complementary DNA sequence and expression in normal and transformed cells. Nature 316: 701-705, 1985.

18. De Bleser PJ, Niki T, Rogiers V and Geerts A: Transforming growth factor-beta gene expression in normal and fibrotic rat liver. J Hepatol 26: 886-893, 1997.

19. Thompson NL, Flanders KC, Smith JM, Ellingsworth LR, Roberts $\mathrm{AB}$ and Sporn MB: Expression of transforming growth factor-beta 1 in specific cells and tissues of adult and neonatal mice. J Cell Biol 108: 661-669, 1989.

20. Nagy P, Schaff $Z$ and Lapis K: Immunohistochemical detection of transforming growth factor-beta 1 in fibrotic liver diseases. Hepatology 14: 269-273, 1991.

21. Salbert G, Fanjul A, Piedrafita FJ, Lu XP, Kim SJ, Tran P and Pfahl M: Retinoic acid receptors and retinoid $X$ receptor-alpha down-regulate the transforming growth factor-beta 1 promoter by antagonizing AP-1 activity. Mol Endocrinol 7: 1347-1356, 1993.

22. Okuno M, Moriwaki H, Imai S, Muto Y, Kawada N, Suzuki Y and Kojima S: Retinoids exacerbate rat liver fibrosis by inducing the activation of latent TGF-beta in liver stellate cells. Hepatology 26: 913-921, 1997.

23. Baer HU, Friess H, Abou-Shady M, Berberat P, Zimmermann A, Gold LI, Korc M and Buchler MW: Transforming growth factor betas and their receptors in human liver cirrhosis. Eur J Gastroenterol Hepatol 10: 1031-1039, 1998.

24. Voumvouraki A, Koulentaki M, Tzardi M, Sfakianaki O, Manousou P, Notas G and Kouroumalis E: Increased TGF- $\beta 3$ in primary biliary cirrhosis: an abnormality related to pathogenesis? World J Gastroenterol 16: 5057-5064, 2010.

25. Morii M, Mezaki Y, Yamaguchi N, Yoshikawa K, Miura M, Imai K, Yoshino H, Hebiguchi T, Hebiguchi T and Senoo H: Onset of apoptosis in the cystic duct during metamorphosis of a Japanese lamprey, Lethenteron reissneri. Anat Rec (Hoboken) 293: 1155-1166, 2010. 